\title{
Infecção natural pelo vírus da diarreia viral bovina (BVDV) em bovinos de corte no Estado do Pará
}

\author{
Natural Infection of Bovine Viral Diarrhea Virus (BVDV) in the Beef Cattle from the Eastern Amazon Region \\ Rinaldo Batista Viana', Claudia Del Fava², Marcus Luciano Guimarães Rezende ${ }^{3}$, Washington Luiz Assunção \\ Pereira', Bruno Moura Monteiro ${ }^{4}$, Rodrigo dos Santos Albuquerque ${ }^{5}$ \& Edviges Maristela Pituco ${ }^{6}$
}

\begin{abstract}
Background: Bovine viral diarrhea virus (BVDV) is a pathogen that causes great economic losses in dairy and beef herds. The main disturbances caused by this virus are related to abortion, fetal malformation and mummification, and the birth of weak calves. In addition, this disease may result in persistently infected animals, as well as individual immune tolerance to the virus. However, the symptoms are nonspecific and variable, and dependent on the age of affected animal. The objective of the present study was to report three cases with clinical signs of BVDV infection, with subsequent confirmation of the diagnosis by reverse transcription - polymerase chain reaction technique (RT-PCR).

Cases: In a beef production farm located at the state of Para, Brazil, three animals presented severe diarrhea; the feces were liquefied and greenish-yellow in color; crusted lesions were visible and scattered over various parts of the animals' bodies, including the muzzle, nostrils, periauricular region, and hooves; the tongue mucosa was undergoing an intense desquamation process. One of the affected animals, a 6-month-old calf, was euthanized following the recommendations of the "Brazilian guide to good practices for animal euthanasia" of the Ethics, Bioethics and Animal Welfare Committee / Federal Council of Veterinary Medicine. After euthanasia, this calf was necropsied and some of its organs, including the tongue and skin, were sent to the Biological Institute of Sao Paulo State for histopathology examination (HE) and identification and isolation of the virus. Positive samples for the presence of BVDV were diagnosed by RT-PCR, confirming the suspicion and explaining the signs observed in that animal and reported in other dead animals of the farm. Because RT-PCR was performed in ulcerative lesions present in the tongue, negative reactions were detected for bovine herpesvirus (BoHV) and positive reactions for BVDV. The cutaneous tissue was marked with lymphocytic infiltration, observed in both epidermis and dermis, which refers to crusted lesions distributed in several regions of the animal's body. In the lungs, we observed rare areas of emphysema and marked lymphocytic interstitial pneumonia with hemorrhagic spots, correlated with symptoms of respiratory disease. Also, marked renal damage and spleen lesions were identified, indicating glomerulonephritis and lymphocytic splenitis.

Discussion: This study evidenced the occurrence of BVDV in two calves and one adult animal, which is in agreement with the described higher incidence of symptomatic infection in young animals. Clinical signs of severe greenish-yellow diarrhea and crusted lesions distributed throughout several regions of the animals' bodies, including the muzzle, nostrils, periauricular region, and hooves were described, with intense tongue epithelium desquamation, which is a particular and characteristic symptom of Mucosal Disease - the classical form of the physiopathogeny caused by bovine viral diarrhea virus. The clinical findings of severe diarrhea are possibly related to the histopathological results, which showed hyalinization of the intestinal mucosa and rare mononuclear cells in the liver nodules. Pulmonary histopathological findings of rare areas of lymphocytic interstitial pneumonia, severe emphysema, and hemorrhagic foci refer to respiratory diseases. Based on the clinical signs and laboratory findings, we conclude that the affected animals showed classic symptoms of bovine viral diarrhea. This diagnosis highlights the presence of the disease in cattle raised in the state of Para, Brazil.
\end{abstract}

Keywords: bovine virus, RT-PCR, Amazon.

Descritores: virose bovina, RT-PCR, Amazônia. 
R.B. Viana, C. Del Fava, M.L.G. Rezende, et al. 2017. Infecção natural pelo vírus da diarreia viral bovina (BVDV) em bovinos de corte no Estado do Pará.

Acta Scientiae Veterinariae. 45(Suppl 1): 181.

\section{INTRODUÇÃO}

Pertencente à família Flaviviridae, gênero Pestivirus, o vírus da diarreia viral bovina (BVDV) é um dos principais patógenos de bovinos, responsável por grandes perdas econômicas na pecuária [9]. As alterações provocadas pelo BVDV são mais acentuadas no sistema reprodutivo, podendo ser observados desde abortamentos, mumificações, malformações fetais até o nascimento de bezerros fracos, persistentemente infectados e imunotolerantes ao vírus $[3,6,8,12]$.

A infecção pelo BVDV tem sido associada a uma ampla variedade de manifestações clínicas: desde infecções inaparentes ou com sinais leves até doença aguda fatal. No entanto, a maioria das infecções em animais imunocompetentes parece cursar de forma assintomática. Entre as consequências mais frequentes da infecção estão a enfermidade gastroentérica aguda ou crônica, a doença respiratória em bezerros, a síndrome hemorrágica com trombocitopenia, as doenças cutâneas e imunossupressões [2,7].

Os bovinos jovens são mais susceptíveis à infecção, mas os adultos podem desenvolver uma doença grave, se infectados com os genótipos altamente virulentos do vírus [14]. Os animais acometidos apresentam-se deprimidos, anoréxicos, com salivação, febre $\left(40-41^{\circ} \mathrm{C}\right)$, taquicardia e polipnéia, descargas nasal e ocular, úlceras na boca, diarreia profusa hemorrágica, desidratação, depressão e morte $[10,13,14]$.

Nesse sentido, objetivou-se relatar três casos clínicos de dois bovinos jovens e um adulto que apresentaram sinais clínicos e suspeita de infecção pelo BVDV, que foi diagnosticado posteriormente por meio da técnica de transcrição reversa e reação em cadeia de polimerase (RT-PCR).

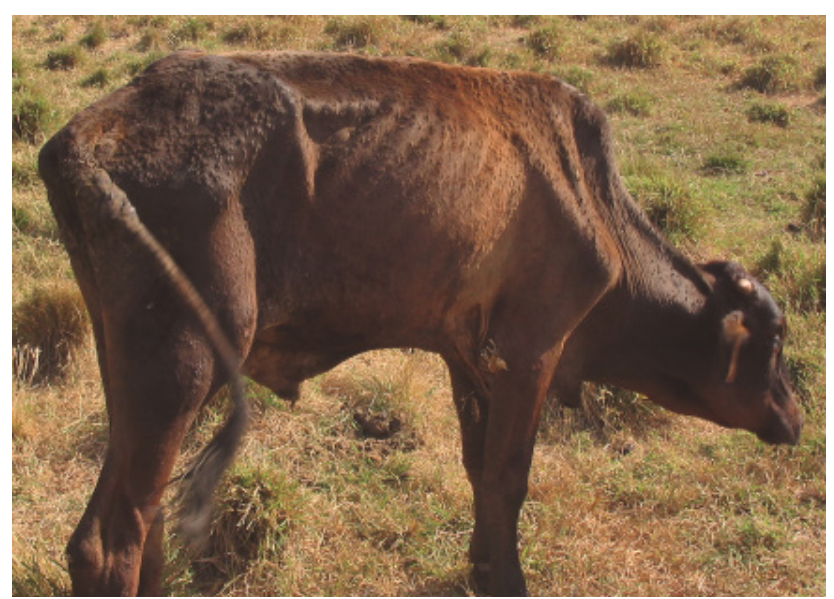

Figura 1. Animal apresentou emaciação progressiva, pelagem seca e áspera
CASOS

Três animais, sendo uma vaca da raça Nelore e dois bezerros mestiços, apresentaram diarreia severa de coloração amarelo-esverdeada com fezes liquefeitas; lesões crostosas distribuídas por várias regiões do corpo do animal, incluindo o espelho nasal, a região peri-auricular, a língua com intensa descamação do epitélio, o espaço interdigital e a coroa dos cascos. O primeiro caso clínico observado na referida propriedade com esses sinais clínicos foi um bezerro mestiço de quatro meses de idade, que morreu dois meses após o surgimento dos sintomas com uma severa diarreia crônica.

Na mesma época, uma vaca primípara da raça Nelore foi eutanasiada pelo Médico Veterinário responsável, por apresentar os mesmos sinais clínicos. Após isso, um bezerro de seis meses de idade, filho dessa vaca, foi atendido, apresentando sinais clínicos semelhantes àqueles descritos nos animais anteriormente atendidos. Este bezerro foi eutanasiado seguindo as recomendações do "Guia brasileiro de boas práticas para eutanásia em animais" da Comissão de Ética, Bioética e Bem-estar Animal/Conselho Federal de Medicina Veterinária [5] e necropsiado, e o material colhido (órgãos, língua e pele) deste único animal foi encaminhado para pesquisa virológica de herpesvírus bovino (BoHV) e do vírus da diarreia viral bovina (BVDV) e exame histopatológico no Instituto Biológico de São Paulo. Foi realizada para detecção de BoHV-1 a PCR e para BVDV a transcrição reversa e reação em cadeia da polimerase (RT-PCR).

Nas erosões ulcerativas presentes na língua foram detectadas reações negativas para BoHV através de PCR e reações positivas para BVDV, pela RT-PCR, confirmando os sinais clínicos observados no animal examinado e relatados nos demais animais mortos na propriedade.
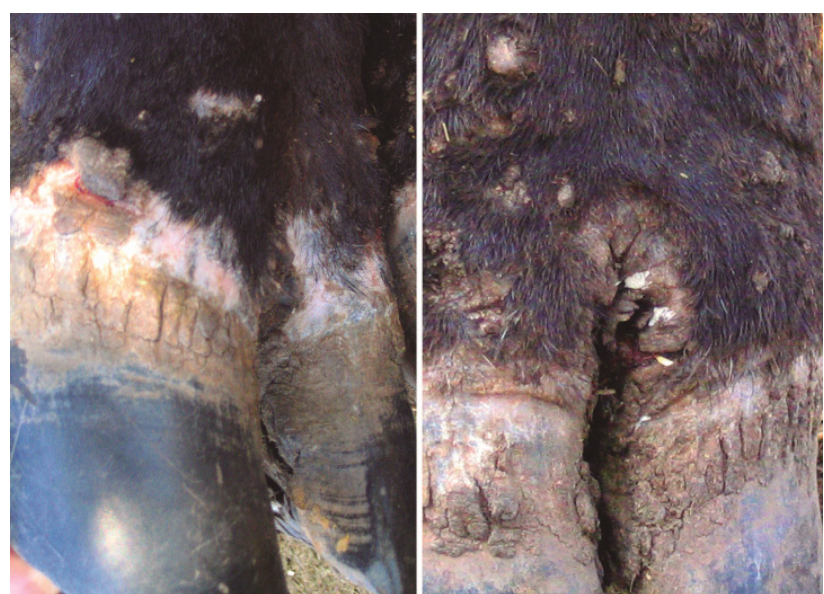

Figure 2. Deformidades dos cascos com lesões ulcerativas sobre a coroa e espaço interdigital. 
R.B. Viana, C. Del Fava, M.L.G. Rezende, et al. 2017. Infecção natural pelo vírus da diarreia viral bovina (BVDV) em bovinos de corte no Estado do Pará.

Acta Scientiae Veterinariae. 45(Suppl 1): 181.

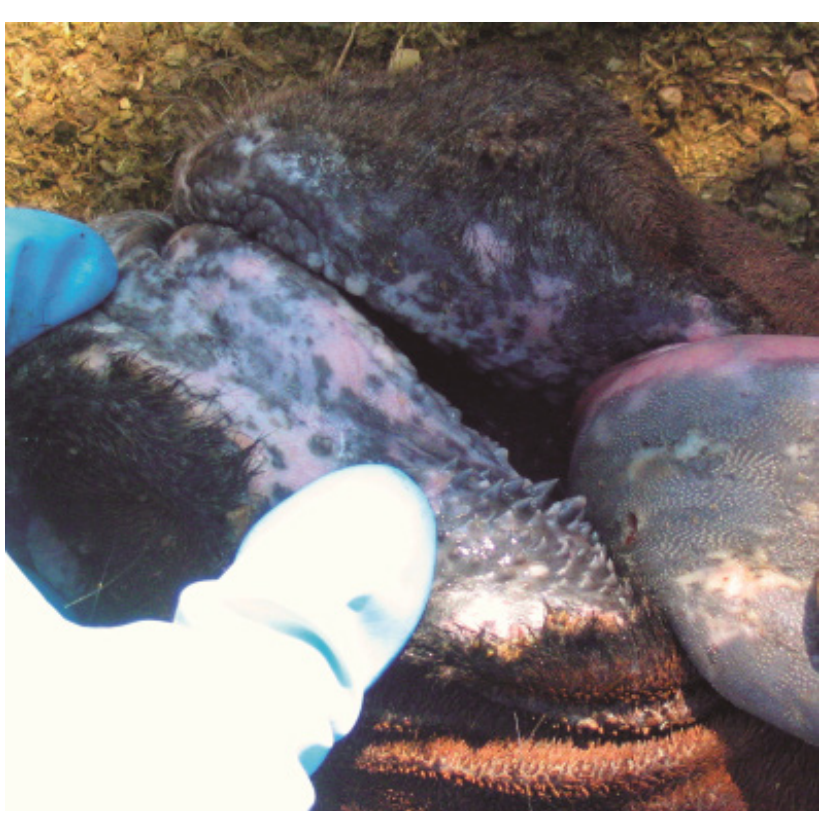

Figura 3. Erosões vesiculares na cavidade bucal e língua.

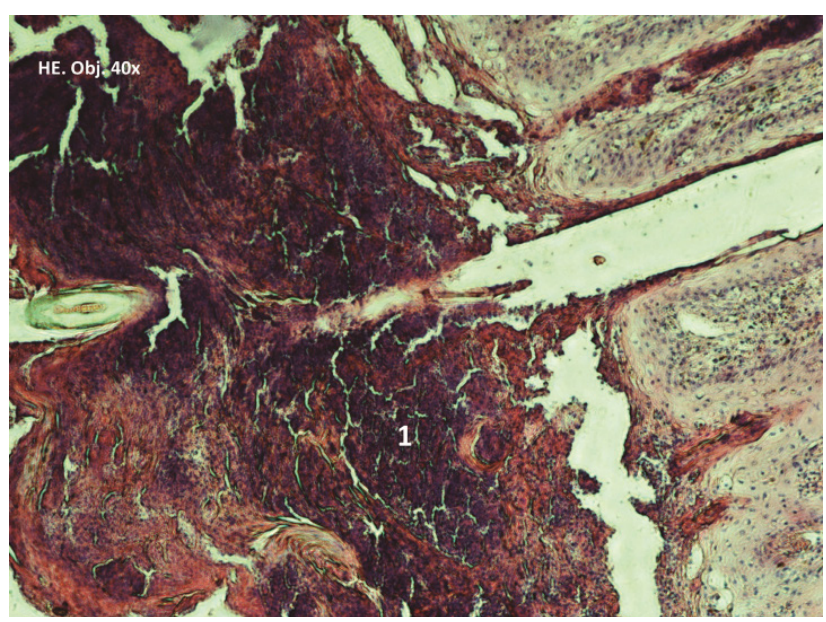

Figura 4. Lesão papulosa cutânea demonstrando formação de crosta epidérmico-queratinica, infiltrada por células inflamatórias (1) [obj. 40x].

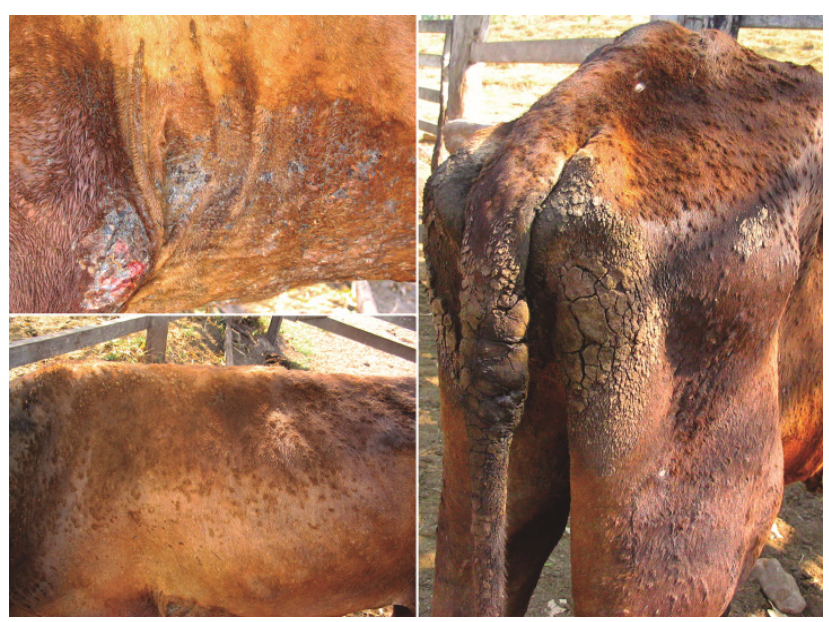

Figura 5. Lesões crostosas cutâneas distribuídas por várias regiões do corpo do animal.
Constatou-se que a doença tornara-se crônica no bezerro necropsiado, pois o animal apresentou emaciação progressiva, pelagem seca e áspera (Figura 1), deformidades dos cascos com lesões ulcerativas sobre a coroa e espaço interdigital (Figura 2) e erosões vesiculares na cavidade bucal e língua (Figura 3) e na pele. No tecido tegumentar foi evidenciada acentuada inflamação de células monolinfocitárias na derme e epiderme (Figura 4), o que faz referência às lesões crostosas cutâneas (Figura 5), distribuídas por várias regiões do corpo do animal. Não foram observados sinais clínicos neurológicos, portanto não evidenciando o envolvimento do BVDV em doença neurológica.

\section{DISCUSSÃO}

Dos três animais atendidos na propriedade, dois deles eram bezerros. Este fato corrobora os achados da literatura nos quais a maioria dos casos de enfermidade causada pelo BVDV ocorrem em animais jovens $[1,4,13,14]$. Lembra-se, porém, que animais adultos também podem ser acometidos pelos sintomas dessa virose quando infectados com genótipos altamente virulentos [14].

Os sinais clínicos verificados - diarreia severa de coloração amarelo-esverdeada com fezes liquefeitas; lesões crostosas distribuídas por várias regiões do corpo do animal, incluindo as narinas, a região peri-auricular, a língua com intensa descamação do epitélio, o espaço interdigital e a coroa dos cascos - são característicos da doença das mucosas $[10,13,14]$, portanto, constituem a forma clássica da diarreia viral bovina.

A diarreia severa de coloração amarelo-esverdeada é compatível com as citações referentes às enfermidades gastroentéricas [1,4,13,14], o que, possivelmente, tem relação com os resultados histopatológicos que mostraram hialinização da mucosa intestinal e raros nódulos de células mononucleares no fígado. Estes achados assemelham-se às descrições de Flores et al. [11], que observaram a presença de úlceras profundas, difusamente distribuídas na mucosa digestiva e infiltrado mono e polimorfonuclear na mucosa e submucosa ruminal e mucosa intestinal e predominantemente por polimorfonucleares na língua.

Alguns estudos fazem referência a doenças respiratórias $[1,4]$, sugestivas aos achados histopatológicos pulmonares de raras áreas de pneumonia intersticial linfocitária e acentuado enfisema e focos hemorrágicos descritos no caso clínico analisado. Ainda, 
R.B. Viana, C. Del Fava, M.L.G. Rezende, et al. 2017. Infecção natural pelo vírus da diarreia viral bovina (BVDV) em

foram identificadas acentuadas lesões esplênicas, histologicamente evidenciando esplenite monolinfocitária. Entretanto, em outra pesquisa foi observado depleção linfóide esplênica [11]. Outras lesões observadas foram alterações renais evidenciadas pela presença de glomerulonefrite.

Baseando-se nos sinais clínicos e alterações patológicas observados nos animais acometidos e nas análises laboratoriais (reações positivas para BVDV, pela RT-PCR) pôde-se concluir que os animais doentes apresentavam um quadro clássico de diarreia viral bovina. Isso evidencia a presença da doença em bovinos no Estado do Pará, Amazônia Oriental, Brasil.

Declaration of interest. The authors report no conflicts of interest.

\section{REFERENCES}

1 Baker J.C. 1995. The clinical manifestations of bovine viral diarrhea infection. Veterinary Clinics of North America. 11(3): 425-445.

2 Bianchi E., Martins M., Weiblen R. \& Flores E.F. 2011. Perfil genotípico e antigênico de amostras do vírus da diarreia viral bovina isoladas no Rio Grande do Sul (2000-2010). Pesquisa Veterinária Brasileira. 31(8): 649-655.

3 Brito W.M.E.D., Alfaia B.T., Caixeta S.P.M.B., Ribeiro A.C.C., Miranda T.M.T., Barbosa A.C.V.C., Barthasson D.L., Linhares D.C. \& Faria B.O. 2010. Prevalência da infecção pelo vírus da diarréia viral bovina (BVDV) no estado de Goiás, Brasil. Revista de Patologia Tropical. 39(1): 7-19.

4 Brownlie J. 1990. The pathogenesis of bovine viral diarrhea virus infections. Scientific and Technical Review of the Office International des Epizooties. 9: 43-59.

5 Conselho Federal de Medicina Veterinária (CFMV). 2013. Guia brasileiro de boas práticas para a eutanásia em animais: conceitos e procedimentos recomendados. Brasília: CFMV, 66 p.

6 Chaves N.P., Bezerra D.C., Sousa V.E., Santos H.P. \& Pereira H.M. 2010. Frequência de anticorpos e fatores de risco para a infecção pelo vírus da diarreia viral bovina em fêmeas bovinas leiteiras não vacinadas na região amazônica maranhense, Brasil. Ciência Rural. 40(6): 1448-1451.

7 Dezen S., Otonel R.A.A., Alfieri A.F., Lunardi M. \& Alfieri A.A. 2013. Perfil da infecção pelo vírus da diarreia viral bovina (BVDV) em um rebanho bovino leiteiro de alta produção e com programa de vacinação contra o BVDV. Pesquisa Veterinária Brasileira. 33(2): 141-147.

8 Dias F.C. \& Sâmara S.I. 2010. Aspectos relevantes da infecção pelo Vírus da diarréia viral bovina (BVDV). Arquivo do Instituto Biológico. 72(1): 1-9.

9 Fauquet C.M., Mayo M.A., Maniloff J., Desselberger U. \& Ball L.A. 2005. Virus Taxonomy: Classification and Nomenclature of Viruses. 8th Report of the International Committee on the Taxonomy of Viruses. San Diego: Elsevier-Academic Press, 1162p.

10 Flores E.F. 2003. Vírus da diarreia viral bovina (BVDV). Arquivo do Instituto Biológico. 65(1): 11-17.

11 Flores E.F., Weiblen R., Scherer C.F.C., Gil L.H.V.G., Pilati C., Dreimeier D., Moojen V. \& Wendelstein A.C. 2000. Identificação do vírus da diarreia viral bovina tipo 2 (BVDV-2) no Sul do Brasil. Pesquisa Veterinária Brasileira. 20(2): 85-89.

12 Lanyon S.R., Hill F.I., Reichel M.P. \& Brownlie J. 2014. Bovine viral diarrhoea: Pathogenesis and diagnosis. The Veterinary Journal. 199: 201-209.

13 Marques D.C. 2003. Criação de Bovinos. 7.ed. Belo Horizonte: Consultoria Veterinária e Publicações, 479p.

14 Radostits O.M., Gay C.C., Blood D.C. \& Hinchcliff K.W. 2002. Clínica Veterinária: um tratado de doenças dos bovinos, ovinos, suínos, caprinos e eqüinos. 9.ed. Rio de Janeiro: Guanabara Koogan, 1170p. 